\title{
ANALISIS AKTIVITAS ANTIOKSIDAN PRODUK SIRUP BUAH MENGKUDU (Morinda citrifolia L.) DENGAN METODE DPPH
}

\author{
Rahmawati, A. Muflihunna, LaOde Muhammad Sarif \\ Fakultas Farmasi Universitas Muslim Indonesia Makassar \\ Email : rama.umifarmasi@gmail.com
}

\begin{abstract}
This research is about antioxidant activity analysis of Noni products syrup (Morinda citrifolia L.) using DPPH (1,1diphenyl-2-picrylhydrazil) method. The research aimed to analysis of antioxidant activity of two different brands of Noni products syrup using spectrophotometer UV-Vis. This analysis using quarcetin as standard to determine antioxidant activity and DPPH reagen as radical sources. Quarcetin and Noni products syrup are made five series concentrations in metanol. One ml of each concentration added $4 \mathrm{ml}$ DPPH $50 \mu \mathrm{M}$ and then added metanol up to 10 $\mathrm{ml}$ in flask. Then incubated for 30 minutes at room temperature and protected from light. Measurement of absorbance using spectrophotometer UV-Vis at $514 \mathrm{~nm}$. The IC $C_{50}$ values were $25.7 \mu \mathrm{g} / \mathrm{mL}$ for brand A, and 9.839 $\mu \mathrm{g} / \mathrm{mL}$ for brand $B$.
\end{abstract}

Keywords: Antioxidant, Noni products syrup, DPPH, spectrophotometer UV-Vis.

\section{PENDAhuluan}

\section{A. Latar Belakang}

Di era globalisasi, kehidupan manusia semakin dimudahkan dengan adanya teknologi, namun tanpa disadari, perkembangan teknologi berbanding lurus dengan perkembangan penyakit. Hal ini disebabkan pola hidup masyarakat yang sering kali membawa dampak negatif pada kebiasaan hidup yang tidak sehat, seperti mengkonsumsi makanan instant, merokok dan mengkonsumsi minuman beralkohol alkohol. Hal itu memicu terbentuknya radikal bebas di dalam tubuh manusia.

Radikal bebas merupakan salah satu bentuk senyawa reaktif, yang secara umum diketahui sebagai senyawa yang memiliki elektron yang tidak berpasangan di kulit terluarnya (Winarsi, 2007). Adanya radikal bebas di dalam tubuh manusia dapat menimbulkan berbagai penyakit degenerative (Prabowo, 2009; Salamah, dkk., 2008). Radikal bebas dapat ditangkal atau diredam dengan pemberian antioksidan atau dengan mengkonsumsi antioksidan (Salimi, 2005; Halliwell, 2007; Kubola \& Siriamornpun, 2008; Mohsen \& Ammar, 2009).

Antioksidan merupakan senyawa pemberi elektron (elektron donor) atau reduktan.Antioksida juga merupakan senyawa yang dapat menghambat reaksi oksidasi dengan mengikat radikal bebas dan molekul yang sangat reaktif. Akibatnya kerusakan sel akan dihambat (Sunardi, 2007).

Mengkudu merupakan salah satu tanaman tropika yang cukup banyak ditemukan diberbagai tempat dan sangat berpotensi sebagai antioksidan alami, karena mengandung flavonoid, triterpen, triterpenoid, dan saponin (Winarsi, 2007; Wang, dkk., 2002).

Antioksidan dibagi menjadi empat tipe berdasarkan fungsinya (Siagian, 2002; Hariyatmi, 2004), yaitu:

1. Tipe pemutus rantai reaksi pembentuk radikal bebas dengan carmenyumbangkan atom $\mathrm{H}$, contohnya vitamin $\mathrm{E}$.

2. Tipe pereduksi yang mampu mentransfer atom $\mathrm{H}$ atau oksigen dan bersifat pemulung, contohnya vitamin C.

3. Tipe pengikat logam yang mampu mengikat zat prooksidan $\left(\mathrm{Fe}^{2+}\right.$ dan $\left.\mathrm{Cu}^{2+}\right)$, contohnya flavonoid, asam sitrat dan EDTA.

4. Antioksidan selular yang mampu mendekomposisi hidrogen peroksida menjadi bentuk stabil, contohnya pada manusia dikenal superoksida dismutase, katalase dan glitation peroksidase.

Hasil penelitian menyebutkan bahwa Morinda citrifolia mengandung komponen bioaktif seperti flavonoid, triterpen, triterpenoid, dan saponin dalam jumlah yang signifikan. Senyawa flavonoid yang terkandung dalam mengkudu bermanfaat sebagai antioksidan (Nayak, dkk.,2010).

Buah mengkudu mengandung alkaloid, antrakuinon, morindin, asam malat, asam sitrat, gum, asam kaprik, dan glukosa (ASEAN Countries, 1993; Depkes RI, 1991). Glukosa berguna sebagai nutrisi, baik bagi pertumbuhan tanaman mengkudu sendiri, maupun bagi makhluk hidup lain yang mengkomsumsi buahnya. Asam kaprik menghasilkan bau yang tidak sedap pada buah mengkudu yang telah matang. Buah 
mengkudu di Indonesia digunakan untuk mengobati beri-beri, asma, diabetes, batuk, mengurangi gangguan menstruasi dan mengobati beberapa masalah pernapasan (Lemmens dan Banyupraphatsara, 2003). Manfaat lain dari buah mengkudu ialah memperlancar pengeluaran urin, membersihkan luka, dan menyembuhkan pembengkakan limpa (Heyne,1987).

\section{METODE PENELITIAN}

\section{A. Alat dan bahan}

Alat-alat gelas (Pyrex), mikropipet, seperangkat alat sentrifuge, spektrofotometri UV-Vis, timbangan analitik.

Aluminium foil, DPPH (1,1-diphenyl-2picrylhydrazil), kuarsetin, methanol p.a, dan produk sirup buah Mengkudu.

\section{B. Prosedur penelitian}

\section{Pengambilan dan pengolahan sampel}

Sampel yang akan diuji dalam penelitian ini berupa produk sirup buah mengkudu (Morinda citrifolia L.)yang beredar di Kota Makassar Provinsi Sulawesi Selatan. Sampel sirup buah mengkudu (Morinda citrifolia L. )didinginkan pada suhu $3-5^{\circ} \mathrm{C}$ selama 24 jam dan disentrifugasi pada $3.000 \mathrm{rpm}$ selama 15 menit dan dipisahkan supernatannya. Supernatant yang diperoleh digunakan sebagai larutan sampel.

\section{Pembuatan Larutan DPPH}

Ditimbang sebanyak 1,97 mgDPPH dan dilarutkan dengan metanol p.a didalam labu sampai $100 \mathrm{mLsehingga}$ diperoleh larutan dengan konsentrasi $50 \mu \mathrm{M}$ (Molyneux, 2004).

\section{Analisis Kualitatif}

Dipipet sebanyak $1 \mathrm{~mL}$ larutan sampel ke dalam tabung reaksi, kemudian tambahkan $4 \mathrm{~mL}$ larutan DPPH $50 \mu \mathrm{M}$ sedikit demi sedikit dan amati perubahan warnanya. Adanya antioksidan ditandai dengan warna yang terbentuk dari masing-masing sampel uji adalah warna kuning (Molyneux, 2004).

\section{Analisis Kuantitatif}

\section{a. Pengukuran Aktivitas Antioksidan Pembanding Kuersetin}

Larutan stok dibuat dengan konsentrasi 1000 ppm. Dibuat dengan cara menimbang $10 \mathrm{mg}$ kuarsetin dan dilarutkan dengan metanol absolut sambil diaduk dan dihomogenkan lalu cukupkan volumenya hingga $10 \mathrm{~mL}$. Selanjutnya dilakukan pengenceran, dipipet $1,0 \mathrm{~mL}$ kemudian dicukupkan dengan metanolabsolut sampai volume akhir $10 \mathrm{~mL}$ (100 ppm). Dari kosentrasi ini (100 ppm) kemudian dilakukan pengenceran lagi, dipipet $1,0 \mathrm{~mL}$ kemudian dilakukan pengenceran hingga $10 \mathrm{~mL}(10$ ppm). Selanjutnya dilakukan pengenceran lagi dengan membuat 5 seri konsentrasi $(0,02 ; 0,04 ; 0,06$; $0,08$ dan $0,1 \mathrm{ppm})$.

Untuk penentuan aktivitas antioksidan, masing-masing konsentrasi larutan dipipet sebanyak $1 \mathrm{~mL}$ dimasukan kedalam tabung reaksi, kemudian tambahkan $4 \mathrm{~mL}$ larutan DPPH $50 \mu \mathrm{M}$. Campuran dihomogenkan dan dibiarkan selama 30 menit ditempat gelap, serapan diukur dengan spektrofotometer UV - Vis pada panjang gelombang $514 \mathrm{~nm}$.

\section{b. Penentuan Aktivitas Antioksidan Produk sirup buah Mengkudu}

Larutan stok dibuat dengan menimbang sampel sirup buah mengkudu (Morinda citrifolia L.) $25 \mathrm{mg}$ dan dilarutkan dengan metanol absolut, dihomogenkan lalu dicukupkan volumenya hingga 25 $\mathrm{mL}$. Selanjutnya dilakukan pengenceran lagi dengan membuat 5 seri konsentrasi larutan $(100,150,200$, 250 dan $300 \mathrm{ppm}$ ).

Untuk penentuan aktivitas antioksidan masing-masing konsentrasi dipipet sebanyak $1 \mathrm{~mL}$ larutan sampel dengan pipet mikrodan masukan ke dalam tabung reaksi, kemudian tambahkan $4 \mathrm{~mL}$ larutan DPPH $50 \mu \mathrm{M}$. Campuran dihomogenkan dan dibiarkan selama 30 menit ditempat gelap, serapan diukur dengan spektrofotometer UV - Vis pada panjang gelombang $514 \mathrm{~nm}$.

Aktivitas antioksidan sampel ditentukan oleh besarnya hambatan serapan radikal DPPH melalui perhitungan persentase (\%) inhibisi serapan DPPH dengan menggunakan rumus (Molyneux, 2004) :

$\%$ Inhibisi $=\frac{(\text { Absorban blanko }- \text { Absorban sampel })}{\text { Absorban blanko }} \times 100 \%$

Keterangan

Absorban blanko : Serapan radikal DPPH $50 \mu \mathrm{M}$ pada panjang gelombang maksimal $(514 \mathrm{~nm})$.

Absorban sampel : Serapan sampel dalam radikal DPPH50 $\mu \mathrm{M}$ pada panjang gelombang maksimal $(514 \mathrm{~nm})$.

Nilai $\mathrm{IC}_{50}$ masing-masing konsentrasi sampel dihitung dengan menggunakan rumus persamaan regresi linier. Konsentrasi sampel sebagai sumbu $\mathrm{x}$ dan $\%$ inhibisi sebagai sumbu $\mathrm{y}$. Dari persamaan: $\mathbf{Y}=\mathbf{a}+\mathbf{b X}$

Untuk penentuan nilai $\mathrm{IC}_{50}$ dapat dihitung dengan menggunakan rumus: $\mathrm{IC}_{50}=\frac{(\mathbf{5 0}-\mathbf{a})}{\mathbf{b}}$

Keterangan :

$\mathrm{Y}=\%$ Inhibisi (50)

$\mathrm{a}=$ Intercept (perpotongan garis di sumbu $\mathrm{Y}$ )

$\mathrm{b}=$ Slope (kemiringan)

$\mathrm{X}=$ Konsentrasi 


\section{HASIL DAN PEMBAHASAN}

\section{A. Hasil}

Tabel 1. Hasil uji kualitatif kandungan antioksidan pada produk sirup buah mengkudu (Morinda citrifolia L.) dengan metode DPPH

\begin{tabular}{|c|c|c|}
\hline Sampel & $\begin{array}{c}\text { Uji Kualitatif } \\
\text { (DPPH 50 } \boldsymbol{\mu M}+\text { sampel) }\end{array}$ & Hasil Pengamatan \\
\hline A & Warna kuning & $(+)$ \\
\hline B & Warna kuning & $(+)$ \\
\hline
\end{tabular}

Keterangan $:(+)=$ kandungan antioksidan

Tabel 2. Hasil uji aktivitas peredam radikal bebas dari kuersetin sebagai pembanding dengan metode DPPH

\begin{tabular}{|c|c|c|c|c|}
\hline $\begin{array}{c}\text { Kosentrasi } \\
\quad(\text { ppm) }\end{array}$ & Absorbansi & $\%$ Inhibisi & IC $_{50}$ & $\begin{array}{c}\text { Aktivitas } \\
\text { Antioksidan }\end{array}$ \\
\hline 0,02 & 0,323 & 42,321 & \multirow{5}{*}{$2,624 \mathrm{~g} / \mathrm{mL}$} & \multirow{5}{*}{$\begin{array}{c}\text { Sangat Kuat }\left(\mathrm{IC}_{50}<50\right. \\
\mathrm{g} / \mathrm{mL})\end{array}$} \\
\hline 0,04 & 0,291 & 48,036 & & \\
\hline 0,06 & 0,275 & 50,893 & & \\
\hline 0,08 & 0,244 & 56,428 & & \\
\hline 0,1 & 0,219 & 60,893 & & \\
\hline
\end{tabular}

Absorbansi Blanko DPPH 514 nm (kuarsetin) = 0,560

Tabel 3. Hasil uji aktivitas peredam radikal bebas produk sirup buah mengkudu merk A dan B dengan metode DPPH

\begin{tabular}{|c|c|c|c|c|c|c|c|c|}
\hline \multirow{2}{*}{$\begin{array}{c}\text { Konsentrasi } \\
\text { sampel } \\
\text { (ppm) }\end{array}$} & \multicolumn{4}{|c|}{ Sampel A } & \multicolumn{4}{|c|}{ Sampel B } \\
\hline & $\begin{array}{l}\text { Abs. } \\
\text { Rata2 }\end{array}$ & $\begin{array}{c}\% \\
\text { Inhibisi }\end{array}$ & $\mathrm{IC}_{50}$ & $\begin{array}{l}\text { Aktivitas } \\
\text { Antioksidan }\end{array}$ & $\begin{array}{l}\text { Abs. } \\
\text { Rata2 }\end{array}$ & $\begin{array}{c}\% \\
\text { Inhibisi }\end{array}$ & $\mathrm{IC}_{50}$ & $\begin{array}{c}\text { Aktivitas } \\
\text { Antioksidan }\end{array}$ \\
\hline 100 & 0,320 & 24,349 & \multirow{5}{*}{$\begin{array}{r}25,700 \\
\mathrm{~g} / \mathrm{mL}\end{array}$} & \multirow{5}{*}{$\begin{array}{c}\text { Sangat Kuat } \\
\left(\mathrm{IC}_{50}<50\right. \\
\mathrm{g} / \mathrm{mL})\end{array}$} & 0,287 & 28,607 & \multirow{5}{*}{$\begin{array}{r}9,839 \\
\mathrm{~g} / \mathrm{mL}\end{array}$} & \multirow{5}{*}{$\begin{array}{c}\text { Sangat Kuat } \\
\left(\mathrm{IC}_{50}<50\right. \\
\mathrm{g} / \mathrm{mL})\end{array}$} \\
\hline 150 & 0,316 & 25,295 & & & 0,270 & 32,836 & & \\
\hline 200 & 0,312 & 26,241 & & & 0,262 & 34,826 & & \\
\hline 250 & 0,306 & 27,659 & & & 0,257 & 36,069 & & \\
\hline 300 & 0,303 & 28,369 & & & 0,247 & 38,557 & & \\
\hline
\end{tabular}

Absorbansi blanko DPPH $514 \mathrm{~nm}($ sampel A $)=0,423$ dan $($ sampel B $)=0,402$ 


\section{B. Pembahasan}

Mengkudu merupakan suatu jenis tanaman yang merupakan genus dari famili Rubiaceae. Mengkudu telah banyak digunakan untuk pengobatan oleh masyarakat dalam bentuk alami maupun sediaan jadi seperti sirup buah mengkudu yang beredar di pasaran. Buah mengkudu banyak mengandung flavonoid, triterpenoid, asam askorbat dan zat-zat lain yang berkhasiat obat, sehingga sangat baik mencegah berbagai penyakit degeneratif. Berdasarkan kandungan kimia buah mengkudu (Morinda citrifoliaL.) antara lain vitamin $\mathrm{C}$ dan flavonoid yang merupakan senyawa yang dapat berpotensi sebagai antioksidan maka perlunya dilakukan analisis aktivitas antioksidan dari sediaan produk buah mengkudu yang beredar di masyarakat metode DPPH menggunakan spektrofotometer UV-Vis.

Metode DPPH adalah metode yang dapat digunakan untuk menentukan aktivitas antioksidan dalam sampel yang akan diujikan dengan melihat kemampuannya dalam menangkal radikal bebas DPPH. Kelebihan metode DPPH ini yaitu metodenya yang sederhana, mudah, cepat, peka, serta memerlukan sampel dalam jumalh kecil. Mudah diterapkan karena senyawa radikal DPPH yang digunakan bersifat relatif stabil dibanding metode lainnya. Prinsip dari metode ini adalah adanya donasi atom hidrogen $\left(\mathrm{H}^{+}\right)$dari substansi yang diujikan kepada radikal DPPH menjadi senyawa non radikal difenil pikril hidrazin yang akan ditunjukkan oleh perubahan warna. Perubahan warna yang terjadi adalah perubahan warna dari ungu menjadi kuning, di mana intensitas perubahan warna DPPH berbanding lurus dengan aktivitas antioksidan untuk meredam radikal bebas tersebut.

Pengukuran aktivitas antioksidan menggunakan spektrofotometer UV-Vis pada panjang gelombang maksimum $514 \mathrm{~nm}$. Pada penelitian ini digunakan pembanding yaitu senyawa kuarsetin dan sampel uji sirup buah mengkudu (Morinda citrifolia L.). Dimana untuk kuarsetin dilakukan pengukuran terhadap 5 seri konsentrasi yaitu 0,$02 ; 0,04 ; 0,06$; 0,08 dan 0,1 ppm. Absorban yang diperoleh digunakan untuk menghitung \% inhibisi menggunakan rumus di atas. Kemudian dilakukan regresi antara \% inhibisi dan konsentrasi kuarsetin. Hasilnya diperoleh kurva baku dengan persamaan $\mathrm{Y}$ $=\mathrm{a}+\mathrm{bX}$, di mana $\mathrm{Y}=38,05+4,553 \mathrm{X} ; \mathrm{R}^{2}=0,992$. Diperoleh nilai a sebesar 38,05 (intersep) dan nilai $\mathrm{b}$ sebesar 4,553 (slope). Selanjutnya dihitung nilai IC $_{50}$ menggunakan rumus di atas dan diperoleh nilai sebesar 2,624 $\mathrm{g} / \mathrm{mL}$.

Pengujian sampel sirup buah mengkudu dilakukan dengan membuat 5 seri konsentrasi yaitu 100, 150, 200, 250 dan 300 ppm, dibuat 3 replikasi.
Lalu pengujian dilakukan seperti pada standar kuarsetin. Untuk sampel A, diperoleh kurva regresi, yaitu $\mathrm{Y}=23,261+1,0404 \mathrm{X}$ dan $\mathrm{R}^{2}=0,9918$. Diperoleh nilai a sebesar 23,261 (intersep) dan nilai b sebesar 1,0404 (slope). Selanjutnya dihitung nilai $\mathrm{IC}_{50}$ dan diperoleh nilai sebesar 25,700 $\mathrm{g} / \mathrm{mL}$. Untuk sampel B, diperoleh kurva regresi, yaitu $\mathrm{Y}=27,239+$ $2,3133 \mathrm{X}$ dan $\mathrm{R}^{2}=0,955$. Diperoleh nilai a sebesar 27,239 (intersep) dan nilai b sebesar 2,3133X (slope). Selanjutnya dihitung nilai $\mathrm{IC}_{50}$ dan diperoleh nilai sebesar 9,839 $\mathrm{g} / \mathrm{mL}$.

Nilai tersebut menunjukkan bahwa sampel A dan sampel B memiliki aktivitas antioksidan sangat kuat, tetapi lebih lemah bila dibandingkan dengan senyawa kuersetin. Sebagaimana dikatakan dalam sebuah penelitian Phongpaichit dkk (2007), bahwa aktivitas antioksidan sangat kuat jika nilai $\mathrm{IC}_{50}<50$ $\mathrm{g} / \mathrm{mL}$, kuat jika nilai $\mathrm{IC}_{50} 50-100 \mathrm{~g} / \mathrm{mL}$, sedang jika $\mathrm{IC}_{50}$ bernilai $100-150 \mathrm{~g} / \mathrm{mL}$, sedangkan jika $\mathrm{IC}_{50}$ bernilai 151-200 $\mathrm{g} / \mathrm{mL}$ dikatakan antioksidannya rendah dan jika $\mathrm{IC}_{50}$ bernilai > $200 \mathrm{~g} / \mathrm{mL}$ maka aktivitas antioksidan yang dimiliki sangat rendah.

\section{KESIMPULAN}

Hasil penelitian dapat disimpulkan bahwa sampel produk sirup buah Mengkudu yang diujikan mengandung dan memiliki aktivitas antioksidan.Dimana nilai $\mathrm{IC}_{50}$ produk sirup buah Mengkudu dari sampel A sebesar25,700 g/mL dan sampelB sebesar $9,839 \mathrm{~g} / \mathrm{mL}$. Dan dinyatakan bahwa aktivitas antioksidan kedua sampel sangat kuat karena masing-masing memiliki nilai $\mathrm{IC}_{50}<50$ $\mathrm{g} / \mathrm{mL}$.

\section{DAFTAR PUSTAKA}

ASEAN, Countries.,1993. Morindae fructus. dalam: Standart Of ASEAN Herbal Medicine (Vol I, Hal. 294-304). Jakarta: ASEAN Countries.

Halliwell, B., 2007. Dietary polyphenols: good, bad, or indifferent for your health. J. Cardiovascular Research 73:341-347.

Hariyatmi.2004.Kemampuan vitamin E sebagai antioksidan terhadap radikal bebas pada lanjut usia. MIPA 14(1):52-60.

Heyne, K. 1987. Morinda citrifolia LINN. dalam : Heyne, K. Tumbuhan Berguna Indonesia (Jilid III, hal. 1795-1799). Jakarta : Badan Litabang Kehutanan.

Kubola, J., Siriamornpun, S.,2008. Phenolic contents and antioxidant activities of bitter gourd 
(Momordica charantia L.) leaf, stem and fruit fraction extracts in vitro. J.Food Chemistry 110:881-890.

Lemmens, R.H.M.J., Bunyapraphatsara, N., 2003. Morinda L. dalam: Lemmens, R.H.J., Bunyapraphatsara, N. Plant Resources of South-East Asia No. 12 (3) Medicinal and poisonous Plants 3 (hal. 302-305). Bogor: Prosea foundation.

Mohsen, S.M., Ammar ASM. 2009. Total phenolic contents and antioxidant activity of corn tassel extracts. J.Food Chemistry 112:595-598.

Molyneux, P., 2004, The Use Of The Stable Free Radical Diphenyl Picrylhydrazyl (DPPH) For Estimating Antioxidant Activity. New York : UJ. Sci. Technol.

Nayak, B., Shivananda, M., Julien R., Isitor, G., dan Adogwa, A., 2010.Hypoglycemic and Hepatoprotektive Activity of Fermented Fruit Juice of Morinda citrifolia (Noni) in Diabetic Rats. Evidence-Based Complementary and Alternative Medicine, Vol. 2011, No. 875293.

Phongpaichit, et al. 2007.Biological Activities of Extracts From Endophytic Fungi Isolated From Garcinia Plants. Chem Pharm Bull : Immunology \& Medical Mycrobiology.

Prabowo,T.T., 2009. Uji aktivitas antioksidan dari keong matah merah (Cerithidea obtusa) [skripsi]. Bogor: Fakultas Perikanan dan Ilmu Kelautan, Institut Pertanian Bogor.

Salamah, E., Ayuningrat,E., Purwaningsih, S., 2008. Penapisan awal komponen bioaktif dari kijing taiwan (Anadonta woodiana Lea.) sebagai senyawa antioksidan. Buletin Teknologi Hasil Perikanan 11(2):119-132.

Salimi, K.Y., 2005. Aktivitas antioksidan dan antihiperkolestrolemia ekstrak beta glukan dari Saccharomyces cerevisiae pada tikus putih. [tesis]. Bogor: Sekolah Pasca Sarjana, Institut Pertanian Bogor.

Siagian, A., 2002. Bahan Tambahan Makanan. Medan: Fakultas KesehatanMasyarakat, Universitas Sumatera Utara.

Sunardi, K.I. Uji aktivitas antioksidan ekstrak belimbing wuluh (Averrhoa bilimbi, L.) terhadap 1,1 diphenyl-2- pycrylhidrazil
(DPPH). Makalah Seminar Nasional Teknologi 2007. Yogyakarta, 24 November 2007.

Wang, M.Y., West, B.J., Jensen, C.J., Nowicki, D., Chen, S., Palu, A.K., dan Anderson, G. 2002.Morinda citrifolia (Noni): Aliterature review and recent advances in Noni research, Acta Pharmacologica Sinica, 23(13): 1127 1141

Winarsi, H., 2007. Antioksidan Alami dan Radikal Bebas; Potensi dan Aplikasi Dalam Kesehatan.Kansius. 